Fecha de recepción: julio 2014

Fecha de aceptación: marzo 2015

Versión final: julio 2015

\section{Poética e inspiración en Diseño de Indumentaria}

Patricia M. Doria *

Resumen: En este texto trataremos de comprender y reflexionar sobre los diferentes mecanismos por los cuales los diseñadores consagrados, o estudiantes en pleno proceso, logran congeniar estos discursos: inspiración, poesía, estilo, identidad, construcción, producto, producción. El diseño es esencia, instante sublime, construcción de imagen realizada a través de un filtro estético y poético que va más allá de su simple descripción. La poética en si misma, se configura como un elemento esencial en el acto de generar un diseño de indumentaria, es el factor que le da el marco diferencial y distintivo. El objeto de indumentaria original nos traslada inmediatamente a algo relativo a su esencia, pudiendo recuperar la apariencia pura para que a lo largo del proceso de diseño pueda convertirse en un objeto de destino. Todo diseño es una actividad que consiste en dar expresión a una forma concebida inmaterialmente y procede según su método. Mientras la idea, vinculada a la fantasía, puede proponer soluciones irrealizables por razones técnicas, materiales o económicas, la creatividad se mantiene en los límites del problema, límites derivados del análisis de los datos y de los subproblemas. Reflexionar sobre la poética significa investigar el futuro del diseño de indumentaria proyectado en el momento en que las condiciones confluyen a un complejo entramado, estético, de investigación, de experimentación, de intuición, de empirismo, de materiales, de tecnologías y de arte.

Palabras clave: poesía - inspiración - moda - indumentaria - tendencia - proyecto - significado.

[Resúmenes en inglés y portugués en las páginas 76-77]

${ }^{(*)}$ Diseñadora de Indumentaria (UBA). Maestría en Diseño (UP). Coordinadora del Área Moda y Profesora en la carrera de Diseño Textil y de Indumentaria de la Facultad de Diseño y Comunicación de la Universidad de Palermo. Forma parte del Equipo de Conducción General y es la coordinadora de la Secretaría de Proyectos Institucionales de la Facultad de Diseño y Comunicación de la Universidad de Palermo. Actualmente es investigadora en el área del color sobre temas de indumentaria (UBA).

Sin importar el análisis y la influencia de las tendencias ni la fuerza comercial y de marketing del producto moda, los diseñadores de indumentaria en sus colecciones siguen buscando en su interior un marco inspiracional propio, desafiante, único, personal, que les 
determine un estilo, una magia singular y significativa. La pregunta es: ¿Cómo lograr esa inspiración tan cercana al mundo del arte, tan propia y sensible, y convertirla en productos de moda usables, repetibles, y vendibles?

En este texto trataremos de comprender y reflexionar sobre los diferentes mecanismos por los cuales los diseñadores consagrados o estudiantes en pleno proceso, logran congeniar estos discursos: inspiración, poesía, estilo, identidad, construcción, producto, producción. En un inicio del proceso resulta imperativo recurrir a la poesía antes de diseñar o conceptualizar un proyecto, reflexionar sobre la poética significa investigar todo el entorno espiritual y los elementos que estimulan ya sean culturales y artísticos sirviendo como instancia de experiencia-inspiracional para el diseñador. Este es un espacio de confluencia entre idea, estética, investigación, experimentación, intuición, empirismo, materiales, tecnologías y arte. El diseño es esencia, instante sublime, construcción de imagen realizada a través de un filtro estético y poético que va más allá de su simple descripción. La poética en sí misma, se configura como un elemento esencial en el acto de generar un diseño de indumentaria, es el factor que le da el marco diferencial y distintivo. El objeto de indumentaria original nos traslada inmediatamente a algo relativo a su esencia, pudiendo recuperar la apariencia pura para que a lo largo del proceso de diseño pueda convertirse en un objeto de destino.

No interesa para nada el objeto indumento aislado, encerrado en sí mismo, a no ser por sus transformaciones conceptuales, irónicas, críticas o puramente estéticas. No son necesarios conocimientos profundos para concebir una acción poética, esta forma estética parte del proceso de elaboración personal del lenguaje de un diseñador de indumentaria, este lenguaje es necesario para que cada elemento del proyecto tenga su significado en el complejo sistema de una colección de moda. La creatividad reemplaza a la idea intuitiva, vinculada todavía a la forma artística-conceptual. La creatividad ocupa el lugar de la idea, el diseñador re-inventa el mundo que lo rodea a través de diferentes medios de abordaje emotivos de su concepto; todo diseño es una actividad que consiste en dar expresión a una forma concebida inmaterialmente. Mientras la idea vinculada a la fantasía, puede proponer soluciones irrealizables por razones técnicas, materiales o económicas, la creatividad se mantiene en los límites del problema, límites derivados del análisis de los datos y de los subproblemas. Reflexionar sobre la poética significa investigar el futuro del diseño de indumentaria proyectado en el momento en que las condiciones confluyen en una red de vinculación entre lo estético, la investigación, la experimentación, la intuición, el empirismo, los materiales, las tecnologías y el arte.

Al diseñar, la persona no sólo tiene en cuenta aspectos estéticos, sino también cuestiones funcionales, técnicas, constructivas y de mercado. Esto exige a los diseñadores estudios, investigaciones y tareas de proyectación que les permita encontrar la manera más original de desarrollar el objeto que pretenden crear.

La función del diseñador es transmitir una idea, un concepto o una imagen de la forma más eficaz posible. Para esto, el diseñador debe contar con una serie de herramientas como la información necesaria de lo que se va a transmitir, los elementos adecuados, su imaginación y todo aquello que pueda servir para su comunicación y uso.

Se presenta como fundamental para este en el proceso de creación, recurrir a la poesía antes de diseñar o conceptualizar un proyecto, reflexionar sobre la poética significa investigar 
su entorno, intereses y los elementos que lo estimulan, su cultura, vivencias, sensaciones, placeres y displaceres, siendo todo esto capitalizado como una instancia de experienciainspiracional para su proyecto. Este cúmulo de experiencias y sensaciones se convierten en un espacio de confluencia estética, investigativa, experimental, intuitiva, empírica, constructiva, tecnologíca y artística. Este proceso de creación expresa por consiguiente en palabras e imágenes lo que podemos saber sobre el futuro proyecto de diseño en general. Esta construcción teórica forma parte del diseño en el que las palabras se utilizan como material y en el que se sigue cierto orden de una experiencia transmisible mediante la actividad narrativa que acompaña al ejercicio activo concreto de la creatividad. El diseño se constituye como una estructuración relacional de diferentes elementos que cuentan y presuponen un acto ordenador, entre lo deseado y lo sabido. Es decir, a las necesidades del tiempo: minimalismo, purismo, funcionalismo, deconstructivismo, maximalismo... el proceso es mas bien inverso se seleccionan y ordenan aquellos datos de la realidad que sirven para justificar el tipo de soluciones que nuestras inclinaciones emotivas e intelectuales normalmente privilegian. En el mundo del diseño de indumentaria el objeto proyectado pertenece a un contexto, cada vez más global, pero igualmente definido en el tiempo y ese tiempo lo marca la tendencia.

En el ámbito del diseño es muy importante el factor psicológico para conseguir el propósito que se busca: crear fantasías y seducir. Por tanto, hay que tener en cuenta lo que puede llegar a expresar o transmitir un color, una forma, un tamaño, una imagen o una disposición determinada de los elementos que posee un diseño de indumentaria, porque en ello está implícita nuestra comunicación. El diseñador coloca en el diseño su emoción y al mismo tiempo la proyecta. La ideología y la ética del diseñador pasan por cargar con antelación la imagen con significados. Nuestro diseño debe constituir un todo, donde cada uno de los elementos comunicacionales que utilicemos posea una función específica, sin interferir en importancia y protagonismo a los elementos restantes a menos que esa sea la intención del diseñador.

La creatividad ocupa el lugar de la idea y procede según su método. Mientras la idea, vinculada a la fantasía, puede proponer soluciones irrealizables por razones técnicas, materiales o económicas, la creatividad se mantiene en los límites del problema, límites derivados del análisis de los datos y de los subproblemas. En ambos casos, se consigue por medio de la atracción, motivación o interés. (....) "En cuanto el creador vio, mostró, descubrió, expreso, realizó de una manera como antes nadie lo había hecho, y esto es independiente del alcance real o artificial de la obra y de su creador". (Zatonyi, 1993, p. 141)

El diseño a través de la acción proyectual no sólo se da a ver, sino se da a entender... nos cuenta historias, habla de nuestro entorno y pensamiento y se aleja de la pura visualidad, se emociona, se identifica. Si bien, en general, el diseño no se consideran como un arte, sino más bien como la prefiguración, o la búsqueda de una solución en un campo específico; sí se puede considerar un arte cuando estas tres características esenciales: creatividad, funcionalidad y productividad se conjugan, en el caso específico de la moda, en una prenda, un look o una colección.

Esta etapa del proceso creativo, es donde el diseñador ejerce el control más fuerte sobre su trabajo y donde tiene la mayor oportunidad de expresar el estado de ánimo y las influencias estéticas totales que requiere transmitir. 
La palabra concepto puede definirse como una idea generalizada, una imagen mental. No existen reglas es la comprensión en términos de significado si disponemos las partes de determinadas maneras para obtener una organización y una orquestación de los medios visuales.

Quienes trabajamos la identidad de una colección de diseño de indumentaria sabemos la mayor fuerza que tienen los aspectos emotivos sobre los racionales. En un producto que no es de pura necesidad y en el que la elección no determina una garantía irrevocable, nos sentimos arrastrados por el atractivo emocional que nos proporciona esta elección y no otra. Las indumentarias que conforma una colección devienen de una expresión y representación de la constitución de un concepto que puede ser representado por un poliedro entendido como una conjunción de formas, que redefinen al diseño y lo enriquecen.

Si algo distingue la estética del diseño es que esta deviene de la capacidad creativa de un diseñador. La presencia de las selecciones y decisiones compositivas marcan el propósito y el significado de las elecciones de las texturas, formas y colores con implicancias sobre su totalidad estética. El diseño vive y se desarrolla con nuevas ideas y con la reinvención de nuestra historia. Partiendo de la intuición e interpretación de experiencias cotidianas y fenómenos de la naturaleza, el diseñador utiliza las herramientas que dispone, y las nuevas tendencias, para interpretar, imitar, superar y dominar a través de su diseño, la realidad circundante.

La elección del concepto dependerá de la consideración de las características particulares del proyecto específico de que se trate: tipo y usuarios, universo del usuario, tendencias, contexto donde se emplazará el proyecto, disponibilidad de recursos ergonométricos, y tecnológicos, en los cuales está incluido el significado.

El diseño de indumentaria en forma emocional establece un diálogo con el futuro usuario, vinculándolo emotivamente más allá de la funcionalidad, de los valores ideológicos/formales, y de la tendencia imperante en un momento social específico; lo que nos atrapa de un diseño es el modo en el que se nos presenta delante de nuestra sensibilidad.

El diseño de indumentaria es un concepto complejo y polifacético: que involucra la optimización funcional, ecológica, ergonómica y de uso, son todos aspectos que conciernen a la actividad del diseñador, y son requerimientos que en la actualidad exigimos en un objeto de indumentaria que suponemos es de buen diseño.

En el diseño, en su etapa conceptual, las ideas son más relevantes que el emergente. La idea de diseño que es lo que define el desarrollo del proyecto prevalece sobre los aspectos formales y en muchos casos la idea es el proyecto en sí mismo, quedando la resolución final como una excusa. Lo que marca la diferencia esta basado en los límites, así como la letras, música o pintura pueden trabajar las palabras, los sonidos o la armonía de colores, libremente y a partir de una emoción, el diseño tiene una utilidad y como tal esta condicionada por la funcionalidad y cuestiones de mercadeo y de usabilidad que deben armonizarse con la idea estética/conceptual.

Las vivencias que se desarrollan en torno al diseño, van generando lazos afectivos que vinculan emotivamente a los individuos con su vestimenta. La unión afectiva es esencial, pero sin dejar de lado la funcionalidad básica, su ideología o sus significados; lo que más atrae de un objeto indumento es el modo en el que despierta nuestra sensibilidad, deseos, enamorándonos de algo indefinido y ese algo es la manifestación directa de nuestra inspiración, historia, personalidad, y emotividad. 
Elegir libremente un indumento-accesorio, tipología, color, marca se encuentra condicionado por el reflejo que la persona siente de sí mismo en estos caracteres. El indumento elegido forma parte de la personalidad, la imagen y el retrato de sí mismo.

El elegir pone en evidencia la capacidad de percibir, de sentir, de emocionarse e incluso conmoverse ante un objeto deseado. Esta experiencia es evidentemente la misma que aplicamos a cualquier tipo de elección de un objeto útil para nuestro uso personal, que a veces llega más allá de la necesidad que cubre y llegamos a adquirir el producto simplemente porque nos autoidentificamos en él, hasta tal punto que deseamos poseerlo, tenerlo junto a nosotros y disfrutarlo.

Toda teoría exige un cierto nivel de abstracción. Prescindiendo de los casos concretos en los que nuestros conceptos generales se hacen patentes o se expresan, nos elevamos a un nivel teórico. Una teoría general del diseño exige que dejemos a un lado lo que es específico de la indumentaria en sí, para concentrarnos en cambio en lo que quiere decir diseñar en todos los ejemplos que puedan darse y de todas las maneras habidas y por haber, sin diferencias entre ellas.

Aun cuando una teoría puede formularse mejor o peor, más o menos pedagógicamente, exige que evitemos el fijarnos demasiado en las palabras que usamos para formularla y que pensemos sobre todo en lo que las palabras pretenden describir y a lo que se refieren. Quienes trabajamos en dar forma, color y, en definitiva, apariencia visual, material y de comportamiento a un concepto o imagen de un objeto, somos conscientes de la influencia del ambiente, la cultura, la tendencia, los objetos, los caracteres visuales de todo ello, dotándolo de una construcción inteligente, generando una fusión con nuestra afinidad emocional y el espíritu de los objetos proyectados.

$\mathrm{Al}$ diseño se lo puede evaluar como creador de formas estéticas, funcionales, con ideas y valores, formas que se vinculan entre sí, se disfrutan, que dialogan y facilitan el intercambio social, que construyen identidad, que hablan de nuestra historia, formas que nos representan y pueden materializarse en nuestra propia identidad, que responda directamente a nuestra esencialidad.

Este espíritu propio del diseño se enriquece y transforma, cuando se genera un intercambio de cualidades, de valores emotivos entre el diseño y el diseñador. No hay duda de que el valor de prestigio y emotividad que adquieren determinados diseños para el usuario es plenamente concordante con la referencia al diseñador que lo generó. Es decir, se transforma en una metodología propia del pensamiento creativo. Explorar, generar ideas, generar imágenes, crear posibilidades para luego darle forma, para obtener el diseño. Esta conexión intrínseca del discurso de diseño es una cuestión de retórica y comunicación.

Esta demanda de creatividad dentro del diseño de indumentaria se da como respuesta a la necesidad de los diseñadores de alejarse de las tendencias, de encontrar un contrapunto entre tendencias globales representadas en las producciones masivas y la necesidad de diseñar lo único y exclusivo.

Las tendencias deben comprenderse como un factor emocional, intelectual e incluso espiritual pero que afecta a nivel global e internacional, la diferencia y exclusividad única -como vimos en párrafos anteriores- esta dada por búsquedas locales propias y personalizadas.

Según Raymond (2010), en la tendencia existe un rasgo mimético donde los individuos sin saberlo imitan comportamientos, gustos, etc, es como un virus que nos inoculan sin 
darnos cuenta, haciendonos perder rasgos de nuestra personalidad las cuales hacen que nuestros objetos diseñados no sean únicos y personalizados. Este proceso de mímesis hace que repitamos en forma inconsciente esquemas socialmente aceptados. Siguiendo a Raymond él nos dice que imitamos a otros por una cuestión de supervivencia a nivel social, intelectual y cultural, imitar rasgos de otros que fueron ya aceptados, nos facilita la aceptación general, más que nada si esta nos garantiza, ser más competitivos, mas relevantes, y distinguirnos socialmente, porque muchas veces esos diseños o productos los hemos visto en personas con las cuales asociamos esos valores. (Raymond, 2010)

La pregunta es, podemos escaparnos de la influencia del virus de la tendencia global? La respuesta es no, no es posible hacerlo si como diseñadores no estamos atentos a saber que este ya está en nosotros, depende de nuestro estado de consciencia del mismo, para poder exacerbar en nuestra creatividad, poética, y mundo propio interior.

Para que surja con claridad el valor de la individualidad y el carácter atemporal de nuestras construcciones, es importante conocer las realidades que nos rodean, entender la diversidad, desarrollar la capacidad de integración, del conocimiento propio y del entorno, para poder incluir ese conocimiento en nuestras producciones y esto es lo que finalmente le otorgará al producto indumentaria una personalidad y un estilo localista citando nuestra cultura, para de este modo marcar la diferencia con una impronta personal, este proceso deberá estar atravesado por un conocimiento del método proyectual, según Munari “...de qué es lo que hay que hacer para hacer o conocer las cosas, es un valor liberatorio: es un "haz de ti" tu mismo" (Munari, 2013, p. 12). De este modo, se podrán generar productos de diseño de indumentaria innovadores, originales, estratégicos y prospectivos, seducidos e inducidos por nuestra mirada.

\section{Referencias Bibliográficas}

Munari, B. (2013). ¿Cómo nacen los objetos? Apuntes para una metodología proyectual. Barcelona: GG

Espartaco, C. (1993). Arte y Discurso. Buenos Aires: Gaglianone.

Raymond, M. (2010). Tendencias. Londres: Publishing Ltd.

Zatonyi , M. (1993). Diseño Análisis y Teoría. Buenos Aires: Ed. CP67.

Summary: In this paper we try to understand and reflect about the different mechanisms by which established designers or ongoing students manage to get along these speeches: inspiration, poetry, style, identity construction and production. Design is essentially a sublime moment, an image built through an aesthetic and poetic filter that goes beyond the simple description. Poetry itself is configured as an essential element in the act of creating a fashion design; is the factor that gives the differential and distinctive framework. The original clothing object immediately transports us to something related to its essence, and may get back to the pure appearance along the design process to become a target object. Every design is an activity that aims to give expression to a form immaterially 
conceived and that proceeds after its methodology. While the idea-linked to fantasy- may propose unworkable solutions due to technical, material or economical reasons, creativity remains within the limits of the problem, limits derived from analysis of the data and the related problems. Reflecting on poetics means researching on fashion design future projected at the time when conditions converge to a complex framework aesthetic, of research, of experimentation, of intuition, of empiricism, of materials, technology and art.

Key words: poetry - inspiration - fashion - trend - clothing - project - meaning.

Resumo: Neste texto trataremos de compreender e refletir sobre os diferentes mecanismos pelos quais os designers consagrados, ou estudantes em processo, logram conciliar estes discursos: inspiração, poesia, estilo, identidade, construção, produto, produção. O design é essência, instante sublime, construção de imagem feita através de um filtro estético e poético que vai muito além da sua simples descrição. A poética em si mesma se configura como um elemento essencial no ato de gerar um design de indumentária, é o fator que lhe da marco diferencial e distintivo. $\mathrm{O}$ objeto de indumentária original nos translada imediatamente a alguma coisa relativa a sua essência, recuperando a aparência pura para que ao longo do processo de design possa converter-se num objeto de destino. Todo design é uma atividade que consiste em dar expressão a uma forma concebida imaterialmente e procede segundo seu método. Enquanto a idéia, vinculada à fantasia, pode propor soluções irrealizáveis por razões técnicas, materiais ou econômicas, a criatividade se mantém nos limites do problema, limites derivados da análise dos dados e dos subproblemas. Refletir sobre a poética significa pesquisar o futuro do design de indumentária projetado no momento em que as condições confluem num complexo tecido, estético, de pesquisa, de experimentação, de intuição, de empirismo, de materiais, de tecnologias e de arte.

Palavras chave: poesia - inspiração - moda - indumentária - tendência - projeto significado. 